\title{
A percepção das puérperas acerca da violência obstétrica no período parturitivo:
}

\section{Uma revisão integrativa}

\author{
The perception of puerperal about obstetric violence in the parturition period: An integrative \\ review \\ La percepción de puérperas sobre la violencia obstétrica en el período de parto: Una revisión \\ integrativa
}

Recebido: 12/05/2021 | Revisado: 22/05/2021 | Aceito: 25/05/2021 | Publicado: 09/06/2021

Tatyane Ferreira Calvão ORCID: https://orcid.org/0000-0002-1092-1044 Hospital Nossa Senhora de Nazareth, Brasil E-mail: taty-calvao@hotmail.com

Bianca Dargam Gomes Vieira ORCID: https://orcid.org/0000-0002-0734-3685 Universidade Federal Fluminense, Brasil

E-mail: biadargam@gmail.com

Valdecyr Herdy Alves

ORCID: https://orcid.org/0000-0001-8671-5063 Universidade Federal Fluminense, Brasil

E-mail: herdyalves@yahoo.com.br

Audrey Pereira Vidal

ORCID: https://orcid.org/0000-0002-6570-9016 Universidade Federal Fluminense, Brasil

E-mail: auviprof@yahoo.com.br

Ana Beatriz Azevedo Queiroz

ORCID: https://orcid.org/0000-0003-2447-6137

Universidade Federal do Rio de Janeiro, Brasil

E-mail: abaqueiroz@hotmail.com

Márcia Vieira dos Santos

ORCID: https://orcid.org/0000-0002-1488-7314 Universidade Federal Fluminense, Brasil

E-mail: enfa.marcia52@gmail.com

Gabriella Cardoso Rodrigues Rangel

ORCID: https://orcid.org/0000-0003-3817-3276 Universidade Federal Fluminense, Brasil E-mail: gabriellacardosorr@gmail.com

\begin{abstract}
Resumo
Objetivo: Identificar e analisar o conhecimento científico brasileiro produzido sobre as percepções das puérperas a respeito da violência obstétrica institucional no período parturitivo. Método: Trata-se de uma revisão integrativa. Para a seleção dos artigos utilizou-se as bases de dados: LILACS, MEDLINE, SCIELO e BDENF. Resultados: Foram selecionados 7 artigos, dos quais emergiram três categorias: Violência de caráter psicológico: seus modos e repercussão, Violência de caráter físico e os procedimentos desnecessários e Violência institucional e a violação dos direitos da mulher. Conclusão: Sensibilização dos profissionais e instituições de saúde quanto à importância da humanização do parto e nascimento.
\end{abstract}

Palavras-chave: Enfermagem; Saúde da mulher; Obstetrícia; Violência.

\begin{abstract}
Objective: Identify and analyze the Brazilian scientific knowledge produced on the perceptions of the puerperal women regarding institutional obstetric violence in the parturitive period. Method: This is an integrative review. For the selection of articles, the following databases were used: LILACS, MEDLINE, SCIELO and BDENF. Results: Seven articles were selected, from which three categories emerged: Violence of a psychological nature: its modes and repercussions, Violence of a physical character and unnecessary procedures and institutional violence and the violation of women's rights. Conclusion: Sensitization of health professionals and institutions regarding the importance of humanizing childbirth and birth.
\end{abstract}

Keywords: Nursing; Women's Health; Obstetrics; Violence. 


\begin{abstract}
Resumen
Objetivo: Identificar y analizar el conocimiento científico brasileño producido sobre las percepciones de las puérperas sobre la violencia obstétrica institucional en el período de parto. Método: Ésta es una revisión integradora. Para la selección de artículos se utilizaron las siguientes bases de datos: LILACS, MEDLINE, SCIELO y BDENF. Resultados: Se seleccionaron siete artículos, de los cuales surgieron tres categorías: Violencia de carácter psicológico: sus modos y repercusiones, Violencia de carácter físico y procedimientos innecesarios y Violencia institucional y la violación de los derechos de las mujeres. Conclusión: Sensibilización de profesionales e instituciones de salud sobre la importancia de humanizar el parto y nacimiento.
\end{abstract}

Palabras clave: Enfermería; Salud de la Mujer; Obstetricia; Violencia.

\title{
1. Introdução
}

De acordo com a Organização Mundial da Saúde (OMS) grande parte das mulheres acaba vivenciando abusos, desrespeito, maus tratos e negligência do período parturitivo. Apesar de estas vivências poderem ocorrer em qualquer momento do ciclo gravídico-puerperal, as mulheres acabam sendo mais vulneráveis durante o parto. O relato dos agravos descreve a ocorrência de violência física, psicológica e verbal, intervenções profissionais coercitivas e não consentidas, quebra de sigilo, não administração de analgésicos, negação de internação, negligências que levam a complicações e dentre outras (Organização Mundial da Saúde, 2014).

A violência obstétrica institucional é a mais discutida por ser exercida pelas equipes de saúde e por acabar sendo consentida pelas mulheres em trabalho de parto mediante o desconhecimento do processo fisiológico parturitivo, a ausência de informações concedidas pelos profissionais sobre as boas práticas de assistência, por temerem a sobrevivência do bebê e também as posições desiguais de autoridade (Santos; Souza, 2015).

Este tipo de violência pode ser reconhecida de diversas formas, principalmente pelo fato de que a grande parte dos partos da atualidade é assistido nos hospitais, podendo ocorrer então desde a admissão da mulher. A peregrinação em busca de atendimento pelos diferentes serviços de saúde, a ausência de acompanhante ou o aceite para que seja de sua livre escolha durante o processo de parto, a escassez de escuta, a falta de tempo, os comentários agressivos, os xingamentos, as ameaças, a discriminação racial e socioeconômica, os exames de toque abusivos, as agressão física e a tortura psicológica são os seus principais exemplos (Cielo et al., 2012).

Em uma pesquisa nacional que ocorreu nos últimos anos, observou-se que cerca de 1/4 das mulheres que pariram e quase metade das que abortaram, relataram alguma das formas de violência obstétrica mencionadas. Entretanto, a ocorrência desses fatos foi apenas a ponta do iceberg, na qual a sociedade tem convivido passivamente (Possati et al. 2017). A Central de Atendimento a Mulher recebeu 75 denúncias de violência obstétrica no ano de 2018, porém entre janeiro a junho de 2019, esse número chegou a 116 (Brasil, 2019).

As repercussões acerca da violência obstétrica na utilização dos serviços de saúde são de extrema preocupação, na forma que a qualidade da assistência recebida afeta as experiências sobre o processo de parir das mulheres e propaga uma cultura social errônea das formas de nascimento, além disso, pode comprometer a visão a respeito dos profissionais que atuam em diferentes contextos (Bohren et al., 2014).

Sendo assim, o presente estudo tem como objetivos identificar e analisar o conhecimento científico brasileiro produzido sobre as percepções das puérperas a respeito da violência obstétrica institucional no período parturitivo.

\section{Metodologia}

O presente estudo trata-se de uma revisão integrativa de literatura e para sua realização foram percorridas seis etapas: (1) identificação do tema e seleção da questão de pesquisa; (2) delimitação de critérios de inclusão e exclusão de estudos; (3) 
definição das informações a serem extraídas desses materiais e categorização dos mesmos; (4) avaliação; (5) interpretação dos resultados e apresentação da investigação e (6) síntese do conhecimento (Mendes et al., 2008).

Desta forma para atender a primeira etapa, identificou-se o tema sobre violência obstétrica e a questão de pesquisa formulada foi “Quais as percepções das mulheres a respeito da violência obstétrica institucional no período parturitivo?”. Para formulação dessa questão utilizou-se a mnemônica PICo, que considerou População: mulheres, Interesse (conceito): percepções sobre violência obstétrica institucional e o Contexto: período parturitivo.

$\mathrm{Na}$ segunda etapa, foram delimitados os critérios para inclusão dos estudos: artigos nacionais de pesquisa referentes à temática, em português, disponíveis na íntegra, publicados entre 2007 e 2017, e de exclusão: textos duplicados, relatos de experiência ou de revisão integrativa de literatura.

A coleta dos dados ocorreu em maio de 2018, na Biblioteca Virtual em Saúde (BVS), a partir das bases: Literatura Latino-Americana e do Caribe em Ciências da Saúde (LILACS), Medical Literature Analysis and System Online (MEDLINE), Scientific Electronic Library Online (SCIELO) e Base de dados em Enfermagem (BDENF), utilizando os descritores: Enfermagem, Violência contra a mulher, Saúde da mulher e Obstetrícia.

Foram identificados 20 artigos, onde apenas 7 atenderam aos critérios pré-estabelecidos.

Na terceira etapa desta revisão integrativa, procedeu-se à definição das informações que foram extraídas dos textos, passando a serem organizados em uma tabela específica (Tabela 1): título do artigo, periódico, país, idioma, ano de publicação, área dos autores, unidade federativa (UF) do estudo, nível de evidência científica, metodologia, objetivos e resultados; que oportunizou identificar os elementos relevantes e dar seguimento com a categorização.

Tabela 1 - Artigos sobre Violência Obstétrica publicados de 2015 a 2017. Rio de Janeiro, RJ, Brasil, 2018

\begin{tabular}{|c|c|}
\hline 1. Título: & Percepções sobre violências obstétricas na ótica de puérperas. \\
\hline Periódico: & Rev enferm UFPE \\
\hline País: & Brasil \\
\hline Idioma: & Português \\
\hline Ano: & 2017 \\
\hline Área dos Autores: & Enfermagem \\
\hline UF: & Bahia \\
\hline Nível de evidência: & Nível IV \\
\hline Método do estudo: & Estudo descritivo, de abordagem qualitativa. \\
\hline Objetivo: & Conhecer a percepção das puérperas no tocante às violências obstétricas. \\
\hline Resultados: & $\begin{array}{l}\text { Emergiram duas categorias após a análise dos dados: "Conhecimentos de puérperas sobre violências } \\
\text { obstétricas", pois, ficou evidente uma percepção restrita do conceito de violências obstétricas, } \\
\text { limitando-as aos atos de caráter psicológico e físico, demonstrando dificuldade em sua definição; e } \\
\text { "Antagonismo na hora do parto: violências obstétricas entrelinhas?" quando traz o cuidado oferecido } \\
\text { pelos profissionais de saúde enquanto condutores desse momento fazendo com que a mulher seja } \\
\text { submissa à equipe e não protagonista de seu parto, ficando notória também a violência psicológica. }\end{array}$ \\
\hline 2. Título: & Relato de puérperas acerca da violência obstétrica nos serviços públicos. \\
\hline Periódico: & Rev enferm UFPE \\
\hline País: & Brasil \\
\hline Idioma: & Português \\
\hline Ano: & 2017 \\
\hline Área dos autores: & Enfermagem \\
\hline UF: & Paraíba \\
\hline Nível de evidência: & Nível IV \\
\hline Método de estudo: & Estudo exploratório, descritivo, com abordagem qualitativa. \\
\hline
\end{tabular}


Objetivo:

\section{Resultados:}

Desvelar as formas de violências obstétricas sofridas durante a gestação e o parto a partir de relatos de puérperas.

No estudo emergiram duas categorias temáticas: "Tipos de violência obstétrica vivenciados na gestação e no parto" como Manobra de Kristeller, relatos de dor e a não utilização de técnicas de alívio quando solicitadas e/ou recomendadas; e "As repercussões da violência obstétrica na vida das mulheres e os principais profissionais envolvidos” em relação aos traumas emocionais sofridos que ficarão marcados na memória das vítimas atrelados ao parir passando por gerações, onde os profissionais mais percebidos são do sexo feminino.

\begin{tabular}{|c|c|}
\hline 3. Título: & Percepção das mulheres sobre violência obstétrica. \\
\hline Periódico: & Rev enferm UFPE \\
\hline País: & Brasil \\
\hline Idioma: & Português \\
\hline Ano: & 2017 \\
\hline Área dos autores: & Enfermagem \\
\hline UF: & Piauí \\
\hline Nível de evidência: & Nível IV \\
\hline Método do estudo: & Estudo descritivo, exploratório, de abordagem qualitativa. \\
\hline Objetivo: & Caracterizar a violência obstétrica vivenciada pelas mulheres durante o processo parturitivo. \\
\hline Resultados: & $\begin{array}{l}\text { Dos relatos das mulheres emergiram duas categorias: "Negligência na Assistência" quando fica } \\
\text { evidente o abandono das parturientes durante o processo parturitivo, sem cuidado e acolhimento; e } \\
\text { "Agressão Verbal" caracterizado por comportamento agressivo, onde palavras danosas são proferidas } \\
\text { à gestante. }\end{array}$ \\
\hline 4.Título: & O direito ao acesso e acompanhamento ao parto e nascimento: A ótica das mulheres. \\
\hline Periódico: & Rev enferm UFPE \\
\hline País: & Brasil \\
\hline Idioma: & Português \\
\hline Ano: & 2017 \\
\hline Área dos autores: & Enfermagem \\
\hline UF: & Rio de Janeiro \\
\hline Nível de evidência: & Nível IV \\
\hline Método de estudo: & Estudo descritivo, exploratório, de abordagem qualitativa. \\
\hline Objetivo: & $\begin{array}{l}\text { Analisar as situações de violência obstétrica perpetrada por profissionais de saúde durante o processo } \\
\text { parto/nascimento sob a percepção das puérperas acerca do direito ao acesso à maternidade e a ter um } \\
\text { acompanhante de sua livre escolha. }\end{array}$ \\
\hline Resultados: & $\begin{array}{l}\text { Foram criadas duas categorias: "A violência obstétrica no campo do parto e nascimento: da falta de } \\
\text { acesso à peregrinação" quando emergem os obstáculos encontrados para ter entrada no serviço de } \\
\text { saúde no componente do parto e nascimento, a carência de transporte seguro e de acolhimento dos } \\
\text { profissionais, confirmando a violência obstétrica de ordem institucional e perpetuando uma violência } \\
\text { psicológica; e "O descumprimento da lei do acompanhante: desrespeito e violação dos direitos } \\
\text { obstétricos" sobre as participantes afirmaram que as unidades de saúde descumprem a Lei do } \\
\text { Acompanhante, o que configura violência obstétrica de caráter institucional, e a desinformação da } \\
\text { mulher quanto a esse direito, durante o processo parturitivo, constitui também uma violência } \\
\text { psicológica na assistência prestada. }\end{array}$ \\
\hline 5. Título: & Violência obstétrica no processo de parturição em maternidades vinculadas à Rede Cegonha \\
\hline Periódico: & Sociedade Brasileira de Reprodução Humana \\
\hline País: & Brasil \\
\hline Idioma: & Português \\
\hline Ano: & 2017 \\
\hline Área dos autores: & Enfermagem \\
\hline UF: & Ceará \\
\hline
\end{tabular}


Research, Society and Development, v. 10, n. 6, e56710616017, 2021

(CC BY 4.0) | ISSN 2525-3409 | DOI: http://dx.doi.org/10.33448/rsd-v10i6.16017

\begin{tabular}{ll} 
Nível de evidência: & Nível IV \\
\hline Método do estudo: & Trata-se de um estudo descritivo com abordagem quantitativa \\
\hline Objetivo: & Analisar a violência institucional contra mulheres no processo de parturição em maternidades \\
& vinculadas a Rede Cegonha de Fortaleza/Cascavel. \\
\hline Resultados: & Participaram da pesquisa 3.765 puérperas de parto vaginal que se encontravam nas unidades de \\
& alojamento conjunto. Em relação às necessidades básicas durante o processo de trabalho, \\
& identificamos que em $70,8 \%$ não ofertaram a ingestão hídrica e em $77,3 \%$ alimentação. No suporte \\
& emocional, $82,9 \%$ relataram o aparecimento de visitas, $67,5 \%$ receberam orientações sobre a parição, \\
& $77,6 \%$ teve a presença do acompanhante por toda a internação e $63,2 \%$ reconheceram que essas \\
& atitudes contribuíram para segurança dos procedimentos, entretanto, não tiveram o acompanhamento \\
& do profissional objetivando conforto físico e emocional. No tocante às intervenções que ocasionaram \\
& sentimentos de hesitação, $89,4 \%$ afirmaram confiança, $67,9 \%$ medo, $28,3 \%$ ordens para pararem de \\
& gritar e $24,6 \%$ apelidos. Dentre as ações que não atendiam as boas práticas referiram $86,7 \%$ manobra \\
& de valsava, $52,2 \%$ exame de toque por profissionais diferentes, $63,8 \%$ uso de soro e $34,5 \%$ uso de \\
& ocitocina.
\end{tabular}

\begin{tabular}{|c|c|}
\hline 6. Título: & Violência Obstétrica sob o olhar das usuárias \\
\hline Periódico: & Rev enferm UFPE \\
\hline País: & Brasil \\
\hline Idioma: & Português \\
\hline Ano: & 2016 \\
\hline Área dos autores: & Enfermagem \\
\hline UF: & Pernambuco \\
\hline Nível de evidências: & Nível IV \\
\hline Método do estudo: & Estudo exploratório, descritivo, com abordagem qualitativa. \\
\hline Objetivo: & Investigar o conhecimento das mulheres acerca da violência obstétrica. \\
\hline Resultados: & $\begin{array}{l}\text { Os depoimentos concedidos possibilitaram a elaboração de duas categorias: "Violência institucional" } \\
\text { onde se observa que muitos profissionais de saúde que participam diretamente do processo de } \\
\text { parturição compreendem que o parto deve ser acompanhado de dor, identificando que algo falta na } \\
\text { prática dentro dos serviços para a humanização do processo parturitivo. "A invisibilidade da } \\
\text { violência obstétrica" quando é possível notar o tratamento desrespeitoso que viola os direitos e a } \\
\text { ausência de humanização no atendimento recebido, além de não assegurar o direito de a mulher ter } \\
\text { um acompanhante de livre escolha e também a realização de procedimentos desnecessários. }\end{array}$ \\
\hline 7. Título: & Violência obstétrica: perfil assistencial de uma maternidade no interior do estado de São Paulo. \\
\hline Periódico: & BDENF \\
\hline País: & Brasil \\
\hline Idioma: & Português \\
\hline Ano: & 2015 \\
\hline Área dos autores: & Medicina \\
\hline UF: & São Paulo \\
\hline Nível de evidências: & Nível IV \\
\hline Método do estudo: & Estudo transversal, descritivo, com abordagem quantitativa. \\
\hline Objetivos: & $\begin{array}{l}\text { Verificar a prevalência de violência obstétrica na Maternidade de um hospital escola e descrever as } \\
\text { características do atendimento. }\end{array}$ \\
\hline Resultados: & $\begin{array}{l}\text { As } 172 \text { participantes da pesquisa representaram } 67,2 \% \text { do universo das } 256 \text { parturientes admitidas na } \\
\text { maternidade no período considerado. O trabalho de parto normal ocorreu em } 39,5 \% \text { dos casos, sendo } \\
32,6 \% \text { o primeiro das mulheres. A assistência da equipe de obstetrícia direcionou } 2,3 \% \text { de conduta } \\
\text { desrespeitosa e repreensiva, esclareceu dúvidas } 83,7 \% \text { e permitiu acompanhante em } 90,7 \% \text {. O } \\
\text { número de procedimentos sem esclarecimento e sem autorização foram } 27,3 \% \text {. No pós-parto } \\
\text { imediato, apenas } 2,3 \% \text { recebeu oportunidade de amamentar o seu bebê. }\end{array}$ \\
\hline
\end{tabular}

Fonte: Autores. 
A avaliação e a interpretação e apresentação dos resultados, respectivamente a quarta e quinta etapas, foram desenvolvidas baseadas em uma análise crítica dos textos selecionados, com foco no agrupamento das informações em relação às convergências e divergências que emergiram sobre temática do estudo.

Na sexta e última etapa da revisão integrativa, foi realizada a apresentação da síntese do conhecimento das evidências disponíveis por meio das categorias criadas.

\section{Resultados}

Mediante a análise dos 7 artigos selecionados nesta revisão, observou-se que 5 deles foram publicados no ano de 2017 (Oliveira; Merces, 2017; Nascimento et al., 2017; Oliveira et al., 2017; Sá et al., 2017; Rodrigues et al., 2017), 1 em 2016 (Silva et al., 2016) e 1 em 2015 (Biscegli et al., 2015). No que diz respeito à área profissional dos autores, 6 (Oliveira; Merces, 2017; Nascimento et al., 2017; Oliveira et al., 2017; Sá et al., 2017; Rodrigues et al., 2017; Silva et al., 2016) foram desenvolvidos por enfermeiros e apenas 1 (Biscegli et al., 2015) por médicos.

Quanto ao nível de evidência científica dos artigos, todos os 7 encontrava-se no nível IV (Oliveira; Merces, 2017; Nascimento et al., 2017; Oliveira et al., 2017; Sá et al., 2017; Rodrigues et al., 2017; Silva et al., 2016; Biscegli et al., 2015). Além disso, de acordo com o método, 5 artigos tiveram abordagem qualitativa (Oliveira; Merces, 2017; Nascimento et al., 2017; Oliveira et al., 2017; Sá et al., 2017; Silva et al., 2016) e 2 quantitativa (Rodrigues et al., 2017; Biscegli et al., 2015), sendo 2 apenas descritivos (Oliveira; Merces, 2017; Rodrigues et al., 2017), 4 descritivos e exploratórios (Nascimento et al., 2017; Oliveira et al., 2017; Sá et al., 2017; Silva et al., 2016) e 1 descritivo e transversal (Biscegli et al., 2015).

No que diz respeito ao estado de condução dos estudos, 1 estudo foi realizado na Bahia (Oliveira; Merces, 2017), 1 na Paraíba (Nascimento et al., 2017), 1 no Piauí (Oliveira et al., 2017), 1 no Rio de Janeiro (Sá et al., 2017), 1 no Ceará (Rodrigues et al., 2017), 1 em Pernambuco (Silva et al., 2016) e 1 (Biscegli et al., 2015) em São Paulo, observando assim o predomínio da abordagem do assunto na região Nordeste.

Em relação aos objetivos identificou-se que todos os estudos versaram sobre a percepção das puérperas acerca da violência obstétrica vivenciada no processo parturitivo (Oliveira; Merces, 2017; Nascimento et al., 2017; Oliveira et al., 2017; Sá et al., 2017; Rodrigues et al., 2017; Silva et al., 2016; Biscegli et al., 2015).

Após a leitura criteriosa dos estudos, realizou-se a análise temática, da qual emergiu as seguintes categorias: "Violência de caráter psicológico: seus modos e repercussão"; "Violência de caráter físico e os procedimentos desnecessários" e "Violência institucional e a violação dos direitos da mulher".

\section{Violência de caráter psicológico: seus modos e repercussão}

Em um estudo $83 \%$ das mulheres revelaram que já sofreram violência obstétrica, porém 39\% destas iniciaram negando esta informação, mas ao responderem os questionários, acabaram identificando já terem vivido este fenômeno, mas que não os compreendiam como tal (Nascimento et al., 2017).

Os profissionais de saúde enquanto condutores do momento do parto atuam como se a parturiente fosse submissa à equipe e não protagonista do próprio processo parturitivo, havendo também a evidente violência psicológica, a qual é velada e mascarada pela naturalização ideológica do poder biomédico sobre a paciente. A mulher é diminuída ao caráter reprodutivo e passa responder apenas em nome do ser gerado, tendo sua autonomia abstraída (Oliveira; Merces, 2017).

Alguns estudos identificaram o descaso que mulheres sofreram de uns profissionais de saúde havendo desse modo agressão psicológica por parte destes (Nascimento et al., 2017; Oliveira et al., 2017; Silva et al., 2016). 
A agressão verbal, caracterizada por palavras danosas, as quais têm a intenção de ridicularizar, humilhar, manipular e/ou ameaçar, causando malefícios psicológicos brutais e irreparáveis foi relatada durante o processo parturitivo, ou seja, o que era para ser um momento agradável, tornou-se uma péssima lembrança às mulheres (Oliveira et al., 2017; Silva et al., 2016).

As mulheres também relataram inúmeros sentimentos relacionados ao processo fisiológico do parto, como medo, raiva, dor, angústia, ódio, estresse e desproteção, todos oriundos da ausência de uma boa assistência (Oliveira; Merces, 2017; Sá et al., 2017; Rodrigues et al., 2017; Silva et al., 2016; Biscegli et al., 2015).

Além disso, em alguns estudos, a falta do cumprimento da Lei do Acompanhante deixaram as mulheres sujeitas à violência de caráter psicológico (Oliveira et al., 2017; Sá et al., 2017).

E ao se tratar do suporte emocional oferecido em uma maternidade em Fortaleza, 82,9\% das mulheres relataram receber visitas, $67,5 \%$ obtiveram orientações sobre o trabalho de parto e parto, 77,6\% tiveram o acompanhante durante todo o tempo de internação e 63,2\% afirmaram que essas atitudes contribuíram para a segurança em relação aos procedimentos, em contrapartida as mesmas, não usufruíram da presença de um profissional que proporcionasse conforto físico e emocional (Rodrigues et al., 2017)

\section{Violência de caráter físico e os procedimentos desnecessários}

A violência obstétrica de caráter físico e a realização de procedimentos desnecessários estavam evidentes em todos os estudos (Oliveira; Merces, 2017; Nascimento et al., 2017; Oliveira et al., 2017; Sá et al., 2017; Rodrigues et al., 2017; Silva et al., 2016; Biscegli et al., 2015). Um deles identificou que a manobra de Kristeller, a ausência de técnicas de alívio quando solicitadas e/ou recomendadas, os exames de toques invasivos, constantes ou agressivos e a utilização da episiotomia sem consentimento foram alguns dos exemplos mais freqüentes destes tipos de violência obstétrica, sendo os profissionais médicos os maiores responsáveis, seguidos pelos enfermeiros (Nascimento et al., 2017).

Grande parte dos profissionais de saúde que atua diretamente na parturição acredita que o parto deve ser acompanhado de dor, até mesmo como punição para que a mulher possa pagar pelo os seus erros (Silva et al., 2016).

Além disso, outro estudo apontou que as ações que caracterizam a não realização das orientações das boas práticas para o parto foram decorrentes de episiotomia, manobra de Kristeller, exame de toque realizado por pessoas diferentes, amniotomia precoce, curagem sem analgesia farmacológica, manobra de Valsava, uso de soro, sonda, ocitocina, tricotomia e enema, e também foi identificado que em 70,8\% dos casos não foram ofertados às mulheres a ingestão hídrica e em 77,3\% a alimentação (Rodrigues et al., 2017).

Ademais, um dos artigos reportou que em uma Maternidade de São Paulo o número de procedimentos realizados pela equipe obstétrica sem esclarecimentos ou sem autorização chegou a ser relatado por 27,3\% participantes (Biscegli et al., 2015).

\section{Violência institucional e a violação dos direitos da mulher}

A fim de escapar da violência institucional, algumas mulheres alegaram se calar diante da dor para que não sofressem mais, através do clássico pressuposto de que se houvesse colaboração e se elas permanecessem quietas, consequentemente seriam melhores atendidas (Oliveira; Merces, 2017).

Outro estudo trouxe os obstáculos encontrados pelas mulheres para conseguir acesso aos serviços de saúde no âmbito do parto e nascimento, além da ausência de transporte seguro durante as peregrinações em busca de atendimento, falta de acolhimento dos profissionais no decorrer do processo parturitivo, configurando violência obstétrica de ordem institucional (Sá et al., 2017). 
Na maioria dos estudos foi descumprido, em graus distintos, a Lei do Acompanhante, desrespeitando e violando os direitos obstétricos (Nascimento et al., 2017; Oliveira et al., 2017; Sá et al., 2017; Rodrigues et al., 2017; Silva et al., 2016; Biscegli et al., 2015).

Como exposto anteriormente, a institucionalização do saber e do poder do profissional de saúde são valorizados nas instituições, tendo superioridade e gerando submissão da mulher e anulação do seu direito ao acompanhante durante o parto e nascimento (Sá et al., 2017).

\section{Discussão}

A partir da análise dos artigos pode-se observar que as puérperas possuem uma compreensão limitada sobre violência obstétrica, muitas vezes apenas a restringindo aos atos de cunho psicológico e físico, havendo certa dificuldade em sua definição e em seu reconhecimento.

A oferta de informação à mulher é um importante meio para que elas consigam sua autonomia no momento do parto. Propõe-se, portanto, que mediante a propagação de esclarecimentos sobre o que seja violência obstétrica e do surgimento e divulgação de políticas públicas de reconhecimento de atos violentos no processo parturitivo, que se resguarde a garantia da parturiente e, principalmente, a possibilidade de denunciar e proteger-se (Vieira; Apolinário, 2017). Assim é necessário ofertar um atendimento individualizado, com apoio emocional e entendimento das questões pessoais objetivando que as mesmas não temam a assistência e nem adquiram sofrimentos futuros.

Durante a gestação e nascimento do bebê ocorrem alterações fisiológicas e hormonais em grandes proporções no organismo feminino para que haja uma adaptação. Desta maneira a mulher deve expressar-se livremente e receber atenção, esclarecimento, respeito e empatia da equipe assistencial, pois quando essas atitudes não estão presentes, o desfecho desses eventos pode acabar tornando-se desfavorável, acarretando em um adoecimento psíquico (Maia et al., 2018).

Ficando claro o quão importante é oportunizar para que a mulher seja protagonista do seu parto, momento único e especial, minimizando desta maneira o risco de desenvolver algum problema de caráter psíquico.

A violência psicológica é uma forma de agressão invisível e cruel contra as mulheres e é uma das mais recorrentes no âmbito médico-hospitalar. Este tipo de violência é caracterizado também por descaso, como privar à parturiente de informações acerca dos procedimentos realizados, oferecer comentários ofensivos, insultosos, discriminatórios, humilhantes e vexatórios, ações grosseiras, agressivas e não empáticas, submetê-las a circunstâncias de medo, abandono, insegurança, recriminação e inferioridade, e dentre outras práticas não recomendadas pela Organização Mundial da Saúde (Sauaia; Serra, 2016).

Em um estudo realizado no Estado de Tocantins, identificou-se que a violência verbal foi à segunda violência obstétrica mais prevalente dentro das maternidades, figurando-se sob a forma de tratamento grosseiro, ameaças, repressões, gritos, humilhações e desrespeito, logo se infere que a violência verbal sofrida pela mulher no momento parturitivo pode gerar a violência psicológica para uma vida toda (Guimarães et al., 2018).

A maioria das mulheres que sofre violência obstétrica relata sentimento de frustração, medo, raiva, anseio e impotência diante da experiência negativa do parto, e estão suscetíveis a desencadear algum transtorno, os quais causam grande impacto físico e psicológico para a vida delas, interferindo na relação com o próprio recém-nascido, com os parentes e amigos, com a sua sexualidade, com a busca por um serviço de saúde e com uma possível próxima gestação (Maia et al., 2018).

No período gravídico e puerperal ocorrem várias modificações nos estados emocionais da mulher, os quais podem culminar em sensações de insegurança e ansiedade frente à nova realidade que se aproxima, deixando-a frágil e vulnerável emocionalmente, o que intensifica a necessidade da presença de uma pessoa de confiança ao seu lado, exercendo o 
companheirismo, a atenção e a afetividade. Logo, quando o direito ao seu acompanhante de livre escolha é violado, sentimentos de medo, angústia, desconfiança e falta de segurança sobre a assistência acabam ocorrendo, contribuindo com situações passíveis para desfechos negativos do processo do parto e nascimento e podendo caracterizar também como violência psicológica (Rodrigues et al., 2017).

Uma atenção de qualidade prestada às mulheres pelos profissionais de saúde pode minimizar as dúvidas, as queixas e também servir de amparo a elas. Assim, o apoio profissional configura-se como um recurso significativo, principalmente pelo vínculo estabelecido, sendo fundamental frente aos aspectos afetivos, estendendo-se para além do corpo da gestante (Zanatta et al., 2017)

Outra prática que poderá levar a malefícios à mulher é a sujeição aos procedimentos desnecessários, dolorosos e que acabam criando maiores riscos para a sua saúde e complicações. A realização desses atos viola seus direitos previstos em leis, na Constituição, além de ameaçar o direito à vida e também propiciam a criação de um cenário de sofrimento, tanto no momento da ação, quanto após, onde danos físicos e psicológicos marcam, de forma negativa, a experiência da parturiente (Martins et al., 2019).

Dessa maneira, o processo parturitivo passa a ser um momento de experiências, na maior parte das vezes, negativas. Consequentemente perdem-se as características de individualidade feminina e de um acontecimento natural, sendo o trabalho de parto encarado pelos trabalhadores da saúde como um evento patológico e propício para as intervenções desnecessárias (Ferreira et al., 2013).

Destaca-se também a violência obstétrica de caráter físico, definida como toda atitude que afete o corpo da mulher, podendo causar dor ou danos físicos, sendo de grau leve a grave, não havendo qualquer necessidade ou recomendação que seja baseada em evidências científicas. Na qualidade de exemplo dessa prática é possível citar a privação de alimentação e movimentação durante o trabalho de parto, a realização da manobra de Kristeller e cesariana eletiva sem indicação (Sipião; Vital, 2015).

Além disso, anteriormente exposto, vários procedimentos médicos são feitos de forma a não serem informados ou esclarecidos à paciente, como o uso de medicamentos para indução do parto e até mesmo a própria episiotomia (Oliveira; Albuquerque, 2018).

Desde a instituição pelo Ministério da Saúde do Programa de Humanização do Parto e Nascimento (2000), e perpassando pela Rede Cegonha (2011) que se constituí em uma rede de cuidados que visa assegurar à mulher o direito ao planejamento reprodutivo e à atenção humanizada à gravidez, ao parto e ao puerpério, bem como à criança o direito ao nascimento seguro e ao crescimento e ao desenvolvimento saudáveis, observa-se a necessidade das equipes de saúde em respeitar a fisiologia do parto evitando assim as intervenções desnecessárias e a vigilância tecnológica intensiva quando não justificadas pelas necessidades da mulher e de seu bebê (BRASIL, 2014; BRASIL, 2013).

A violência obstétrica de caráter institucional também se configura um importante problema, caracterizando-se por ações ou situações que possibilitam um cenário de empecilhos ou retardamento no acesso, e utilização, das mulheres aos seus direitos constituídos (Sipião; Vital, 2015).

Ademais, é perceptível a violação de alguns direitos da mulher de acordo com a Organização das Nações Unidas, como o direito à liberdade e segurança pessoal, à igualdade e a estar livre de todas as formas de discriminação, à liberdade de pensamento, à informação e a educação, à privacidade, à saúde e a proteção desta, aos benefícios do progresso científico e ao de não ser submetida a maltrato (Fiocruz, 2021).

Torna-se evidente a necessidade de mudança na assistência, pois esta deve estar pautada na humanização. As instituições de saúde e as equipes assistenciais, principalmente os enfermeiros obstétricos, os quais normalmente possuem maior vínculo com a mulher, devem acolher as parturientes, seus familiares e bebês com integridade e respeito para que seja 
construído um ambiente que propicie a autonomia feminina e o protagonismo do seu parto (Moura et al., 2018).

De acordo com a Lei $n^{\circ} 11.634 / 2007$ a gestante tem a garantia de ter à vinculação prévia com a maternidade na qual será atendida nos casos de intercorrência e realizará o seu parto, o que se dará no ato de sua inscrição no programa de pré-natal. Sendo assim, esta unidade deverá estar apta a prestar a assistência necessária conforme a situação de risco gestacional, inclusive no puerpério (Brasil, 2007). Ou seja, ao descumprir a Lei mencionada, a instituição viola um direito da mulher, e acaba por cometer violência de caráter institucional.

O direito à presença de acompanhante durante o trabalho de parto, parto e pós-parto imediato no âmbito do Sistema Único de Saúde (SUS), incluindo a rede própria ou conveniada é garantida pela Lei 11.108/2005, pois o Ministério da Saúde tem buscado qualificar a assistência e melhorar a implementação das políticas públicas de saúde que beneficiem o processo parturitivo (Monguilhott et al., 2018). Porém, observa-se que nem sempre as maternidades respeitam esta Lei e muitas mulheres desconhecem essa sua garantia.

\section{Conclusão}

Os estudos indicam que as mulheres não compreendem o conceito e as manifestações da violência obstétrica institucional no período parturitivo, e que as mesmas ficam submetidas, em sua grande maioria, às equipes de saúde durante o processo do parto e nascimento, e a momentos permeados por abusos psicológicos, procedimentos desnecessários e violação de seus direitos, desta forma não coadunando com os embasamentos do Programa de Humanização do Pré-natal e Nascimento e da Lei do Acompanhante.

Desta maneira empoderar as gestantes/parturientes, enquanto atores principais, como também uma ampliação na divulgação, direcionada à população em geral, sobre direitos sexuais e reprodutivos e violência obstétrica se faz necessário para promover a autonomia e satisfação materna e familiar.

Diante disso, também se torna fundamental que os profissionais obstétricos prezem pela humanização do parto e nascimento, e que suas condutas estejam em consonância com a estruturação proposta da Rede Cegonha, evitando assim que mulheres sejam vítimas da violência obstétrica.

E que os gestores de saúde ampliem as discussões sobre violência obstétrica objetivando desenvolver estruturação do sistema de atendimento da unidade, ações de sensibilização e orientação de toda a equipe de obstetrícia, intencionando reconhecer as necessidades das gestantes.

Ademais, sugere-se o desenvolvimento de estudos relativos a estratégias de prevenção, identificação e enfrentamento da violência obstétrica em suas diferentes circunstâncias, âmbitos de ocorrência e momentos do ciclo gravídico-puerperal, visto que o foco maior das pesquisas se dá no momento do parto e nascimento.

\section{Referências}

Biscegli, T. S., Grio, J. M., Melles, L. C., Ribeiro, S. R. M. I., \& Gonsaga, R. A. T. (2015). Violência Obstétrica: Perfil Assistencial de uma Maternidade Escola do Interior do Estado de São Paulo. Cuidart Enfermagem, 9(1):18-25.

Brasil. (2007). Lei $n^{\circ}$ 11.634, de 27 de dezembro de 2007. Dispõe sobre o direito da gestante ao conhecimento e a vinculação à maternidade onde receberá assistência no âmbito do SUS. Diário Oficial da União 27 dez 2007.

Brasil. (2019). Ministério da Mulher, da Família e dos Direitos Humanos. Balanço anual: Ligue 180 recebe mais de 92 mil denúncias de violações contra mulheres. Brasília: Distrito Federal. https://www.mdh.gov.br/todas-as-noticias/2019/agosto/balanco-anual-ligue-180-recebe-mais-de-92-mil-denuncias-deviolacoes-contra-mulheres

Brasil. (2013). Ministério da Saúde. Conheça a Rede Cegonha. http://bvsms.saude.gov.br/bvs/folder/rede_cegonha.pdf

Brasil. (2014). Ministério da Saúde. Universidade Federal do Ceará. Humanização do parto e do nascimento. Ministério da Saúde.

Bohren, M., Hunter, E. C., Munther-Kaas, H. M., Souza, J. P., Vogel, J. P., \& Gulmezoglu, A. M. (2014). Facilitators and barriers to facility-based delivery in low- and middle-income countries: A systematic review of qualitative evidence. Reprod Health, 11(1): 1-17. 
Cielo, C., Carvalho, C., Kondo, K., Delage, D., Niy, D., Werner, L., \& Santos, S. K. (2012). Violência Obstétrica “Parirás com dor”. Brasília: Senado Federal. https://www.senado.gov.br/comissoes/documentos/SSCEPI/DOC\%20VCM\%20367.pdf

Ferreira, A. G. N., et al. (2013). Humanização do parto e nascimento: acolher a parturiente na perspectiva dialógica de Paulo Freire. Rev Enferm UFPE On Line, 7(5):1398-405.

Fiocruz. (2021). Os Direitos da Mulher. http://www.fiocruz.br/biosseguranca/Bis/infantil/direitodasmulheres.htm

Guimarães, L. B. E, Jonas, E., \& Amaral, L. R. O. G. (2018). Violência obstétrica em maternidades públicas do estado do Tocantins. Revista Estudos Feministas, 26(1): e43278.

Maia, J. S., Sant'anna, G. S., \& Menegossi, F. S. (2018). A Mulher Diante da Violência Obstétrica: Consequências Psicossociais. Revista Científica Multidisciplinar Núcleo do Conhecimento, 7(3): 54-68.

Martins, F. L., et al. (2019). Violência Obstétrica: Uma expressão nova para um problema histórico. Revista Saúde em Foco, s/v(11): $413-423$.

Mendes, K. D. S., Silveira, R. C. C. P., \& Galvão, C. M. (2008). Revisão Integrativa: Método de Pesquisa para a Incorporação de Evidências na Saúde e na Enfermagem. Texto Contexto Enferm., 17(4): 758-64.

Moura, R. C. M., et al. Cuidados de Enfermagem na Prevenção da Violência Obstétrica. Enferm. Foco, 9 (4): 60-65.

Monguilhott, J. J. C., Bruggemann, O. M., Freitas, P. F., \& D’orsi, E. (2018). Nascer no Brasil: a presença do acompanhante favorece a aplicação das boas práticas na atenção ao parto na região Sul. Rev Saude Publica, 52(1): 1-11.

Nascimento, L. C., Santos, K. F. O., Andrade, C. G., Costa, I. C. P., \& Brito, F. M. (2017). Relato de Puérperas Acerca da Violência Obstétrica nos Serviços Públicos. Rev Enferm UFPE On Line, 11(5): 2014-23.

Oliveira, L. G. S. M. \& Albuquerque, A. (2018). Violência obstétrica e direitos humanos dos pacientes. Revista CEJ, s/v(75): 36-50.

Oliveira, M. C., \& Merces, M. C. (2017). Percepções sobre Violências Obstétricas na Ótica de Puérperas. Rev Enferm UFPE On Line, 11(6): 2483-9.

Oliveira, T. R., Costa, R. E. O. L., Monte, N. L., et al. (2017). Percepção das mulheres sobre violência obstétrica. Rev Enferm UFPE On Line, 11(1):40-6.

Organização Mundial da Saúde. (2014). Prevenção e eliminação de abusos, desrespeito e maus-tratos durante o parto em instituições de saúde. http://apps.who.int/iris/bitstream/10665/134588/3/WHO_RHR_14.23_por.pdf

Possati, A. B., Prates, L. A., Cremonese, L., Scarton, J., Alves, C. N., \& Ressel, L. B. (2017). Humanização do Parto: Significados e Percepções de Enfermeiras. Esc Anna Nery, 21(4):1-6.

Rodrigues, D. P., et al. (2017). O descumprimento da lei do acompanhante como agravo à saúde obstétrica. Texto Contexto Enferm, $26(3)$ : e5570015.

Rodrigues, F. A. C., Lira, S. V. G., Magalhães, P. H., Freitas, A. L. V., Mitros, V. M. S., \& Almeida, A. P. C. (2017). Violência obstétrica no processo de parturição em maternidades vinculadas à Rede Cegonha. Reprod Clim., 32(2):78-84.

Sá, A. M. P., Alves, V. H., Rodrigues, D. P., Branco, M. R. B. L., Paula, E., \& Marchiori, G. R. S. (2017). O Direito ao Acesso e Acompanhamento ao Parto e Nascimento: A Ótica das Mulheres. Rev Enferm UFPE On Line, 11(7):2683-90.

Santos, R. C. S., \& Souza, N. F. (2015). Violência institucional obstétrica no Brasil: revisão sistemática. Estação Científica UNIFAP, 5(1):57-68.

Sauaia, A. S. S., \& Serra, M. C. M. (2016). Uma dor além do parto: violência obstétrica em foco. Revista de Direitos Humanos e Efetividade, 2 (1): 128-147.

Silva, R. L. V., Lucena, K. D. T., Deininger, L. S. C., et al. (2016). Violência Obstétrica Sob o Olhar das Usuárias. Rev Enferm UFPE On Line, 10(12):447480 .

Sipião, J. P., \& Vital, B. V. S. C. (2015). Violência Obstétrica: O Silêncio das Inocentes. Anais do VIII Encontro de Pesquisa e Extensão da Faculdade Luciano Feijão. https://flucianofeijao.com.br/novo/wp-content/uploads/2016/11/VIOLENCIA_OBSTETRICA_O_SILENCIO_DAS_INOCENTES.pdf.

Vieira D. R., \& Apolinário, J. A. (2017). A violência obstétrica na compreensão de mulheres usuárias da rede pública de saúde do município de Lins. São Paulo. Monografia (Graduação em Psicologia). Unisalesiano. http://www.unisalesiano.edu.br/biblioteca/monografias/61050.pdf

Zanatta, E., Pereira, C. R. R., \& Alves, A. P. (2017). A experiência da maternidade pela primeira vez: as mudanças vivenciadas no tornar-se mãe. Pesquisas e Práticas Psicossociais, 12(3): e1113. 